\title{
PLANEJAMENTO Do ECONOMICISMO MODERNO à Dialética Socioespacial
}

\author{
LUCAS LINHARES
}

R E S U M O A teoria e a práxis do planejamento, nas sociedades capitalistas modernas, refletem a consolidação de um modelo de racionalidade fundado numa visão mecanicista dos processos sociais. A matriz positivista da ciência - que busca enunciar (e predizer) os fenômenos sociais por meio de leis universais - alcançou posiçāo hegemônica e assentou as bases do planejamento moderno. No campo da Economia Politica, dominada pela perspectiva mecanicista embutida na corrente neoclássica, a busca da construção de esquemas teóricos generalistas confere ao espaço, enquanto categoria analitica, um papel secundário. $O$ presente artigo propōe inicialmente uma discussäo epistemológica, buscando avaliar criticamente o significado da incorporaçāo de um paradigma economicista e mecanicista por parte da teoria do planejamento. Entrecortando a discussäo epistemológica, procuramos, amparados na perspectiva teórica neomarxista, reafirmar o papel do espaço como categoria elementar à compreensão dialética da dinâmica capitalista, sem a qual uma teoria do planejamento incorreria em importante lacuna. O reconhecimento de que as contradiçōes do modo de produção devem ser desvendadas pela investigaşão do espaço socialmente engendrado é capaz de nos conduzir a uma teoria social mais robusta no balizamento do planejamento.

P A L A V R A S - C H A V E Planejamento; dialética socioespacial; modernidade; espaço social.

\section{INTRODUÇÃO}

O planejamento da coisa pública (res publica), envolvendo as instâncias social, econômica e espacial, é objeto de atençôes e intençôes desde a antigüidade. Pensadores do quilate de Platão e Aristóteles tinham na politica o arcabouço teórico-prático que fundamenta a atuaçăo do Estado enquanto organismo de governo. Nessa concepção, o principal desígnio do Estado é encontrar a forma de vida ideal, que conduza os cidadãos à virtude e ao seu objetivo supremo: a felicidade. A política, na definiçăa aristotélica, é a ciência da felicidade humana.

Ademais, o corpus teórico-prático aristotélico considerava a cidade (polis) como o objeto por excelência da politica, donde decorre que o meio concebido para o alcance da felicidade passaria necessariamente pela organização da polis, o espaço dos cidadãos. Observamos, pois, que Aristóteles revelava já naqueles tempos a percepção de que a felicidade da coletividade humana é condicionada à edificaçẫo de formas socioespaciais adequadas; formas essas que deveriam ser fomentadas e asseguradas pelo Estado. Assim, identificamos na obra do filósofo estagirita incursões pioneiras no campo do planejamento, ainda que sem o caráter que a modernidade positivista conferiu à matéria séculos mais tarde. Uma vez que se apresentavam esquemas teóricos que requeriam para si o status científico, e que visavam ao balizamento de atuaçôes no campo da praxis, começava a ser sedimentada a idéia do planejamento socioespacial, que, sob o epíteto genérico de politica, versava 
sobre os destinos da polis e, por conseguinte, sobre os destinos da reprodução social e material da humanidade, envolvendo uma dimensão espacial inescapável.

Não obstante, a modernidade interpôs ao germe aristotélico forças contrárias de reação, tanto no plano epistemológico quanto no plano político. Tais forças significaram a tomada das ciências sociais pelo positivismo, que trazia embutida a primazia do indivíduo em detrimento da coletividade e a emergência do liberalismo como doutrina social que garantiria aquela primazia.

No campo da economia política, embora a penetração do paradigma positivista tenha se dado retardatariamente, verificamos a consolidação hegemônica de um modelo de racionalidade fundado numa visão mecanicista da sociedade, como se esta obedecesse aos mesmos ditames das ciências naturais. É justamente a essa "física social" que vai sucumbir o planejamento nas sociedades capitalistas da modernidade.

Em última instância, no esquema teórico mecanicista clássico, a racionalidade do(s) mercado(s) era imposta como virtuosa na consecução dos objetivos sociais, o que tinha como contrapartida, no plano político, a legitimação da ordem liberal-individualista. A suposta existência de indivíduos racionais maximizadores garantiria uma tendência inexorável ao "ótimo social", donde deriva que as ingerências de instrumentos extra-mercado significariam um obstáculo à "harmonia natural dos interesses".

Diante desse quadro, em que a economia política - dominada pela perspectiva da física social embutida na matriz neoclássica - buscava a construção de esquemas teóricos generalistas, o espaço enquanto categoria analítica foi relegado a segundo plano, ao mesmo tempo em que o planejamento reduzia seu escopo ao mínimo, uma vez que, neste mundo ideal, sua presença era praticamente dispensável.

É sabido que a extensão do capitalismo urbano-industrial como modo de produção e reprodução social às mais diversificadas partes do mundo pauta-se por heterogeneidades. A dinâmica do capital no espaço é marcada por uma dualidade centro-periferia, que concentra oportunidades de desenvolvimento em alguns pontos, mantendo outros à margem das benesses do sistema.

Considerando as partes do mundo em que as contradiçóes do capitalismo imprimem uma realidade especialmente adversa, pautada por graves desequilíbrios sociais, econômicos e espaciais, como é o caso do Brasil, cumpre investigar em que medida a matriz epistemológica que formou o alicerce do planejamento na modernidade, bem como seus desdobramentos sobre os esquemas teóricos e práticos contemporâneos, oferecem subsídios para compreender e superar tais adversidades.

Buscamos, portanto, discutir a possibilidade teórica do planejamento e do desenvolvimento. Para tanto, encetamos uma visão segundo a qual o planejamento contempla pelo menos três instâncias: economia, sociedade e espaço. As especificidades do modus operandi dessas três instâncias articuladas explicam a condição de (sub)desenvolvimento. A análise dialética das estruturas sociais, econômicas e espaciais historicamente engendradas fornece elementos para a compreensão da realidade social periférica, constituindo um ponto de partida para pensar os mecanismos de sua superação. Uma análise dessa natureza exige uma apreciação crítica das teorias e políticas do desenvolvimento hegemônicas, afeitas às teleologias generalistas.

É nesse substrato teórico-político, sucintamente descrito acima, que o presente texto se planta. Inicialmente, realizamos uma discussão de cunho epistemológico, ou seja, teorizamos sobre a própria ciência, buscando perscrutar as matrizes científicas que informaram o planejamento na modernidade. Nessa ambiência discursiva, discorremos acerca 
dos impactos da penetração do positivismo nas ciências sociais, e particularmente na economia, sobre a teoria do planejamento. A incorporação de um paradigma economicista e mecanicista pelo planejamento significou, contraditoriamente, seu próprio fenecimento, uma vez que tal paradigma veio a legitimar o liberalismo.

Entrecortando a discussão epistemológica, procuramos reafirmar o papel do espaço como categoria elementar à compreensão da dinâmica capitalista, sem a qual uma teoria do planejamento incorreria em importante lacuna. Com esse propósito, absorvemos dos teóricos neomarxistas elementos para trazer o espaço ao primeiro plano da compreensão dialética da realidade social. A configuração econômico-social é, por princípio, um corpo sistêmico espacialmente referenciado. Mais do que a "cartografia cartesiana da ciência espacial", que não permite ir além da superficialidade concreta do espaço, é preciso aprofundar a substância teórica, reconhecendo a relação dialética entre a configuração espacial e os processos sociais e econômicos; nesse sentido ampliando a discussão sobre planejamento em torno da idéia mais ampla de uma "economia política da produção social do espaço", adutora da dialética socioespacial. Sob essa perspectiva, herdada de Henri Lefebvre, o espaço torna-se a categoria privilegiada para entender a realidade social. $\mathrm{Na}$ medida em que o espaço é concebido como instância realizadora do capital, uma vez que este conforma aquele à lógica de reprodução do sistema, começam a ser reveladas as relações sociais dialeticamente embutidas na configuração espacial.

\section{A EPISTEMOLOGIA DO PLANEJAMENTO NA MODERNIDADE}

O embrião das atividades de planejamento sócio-político, econômico e espacial pode ser identificado, a exemplo de boa parte do conhecimento em ciências sociais, na Grécia Antiga. Simultaneamente aos pródromos de tal exercício político, nasceu o embate de idéias acerca de qual seria a melhor sistemática para tratar das questôes de interesse geral, do governo da res publica.

A Academia platônica era partidária da investigação científica de índole matemática como o pavimento mais sólido para a ação política. A atividade humana, sob essa perspectiva, "requeria uma ciência (episteme) dos fundamentos da realidade na qual aquela ação está inserida". ${ }^{1}$ Destarte, o ideário platônico requeria um arcabouço referencial com status científico, construído pela busca de verdades essenciais sobre o universo.

Aristóteles de Estagira, célebre filósofo que ainda hoje calça o alicerce do ethos e do logos ocidentais, formou-se na Academia platônica, incrementando-a com seu espírito investigativo de observação e uma perspectiva um tanto naturalista. Em sua obra denominada Política, Aristóteles argumenta que o Estado deve se constituir como um organismo moral, procurador da virtude de seus concidadãos. Nesse sentido, a política é a doutrina moral social, coletiva, sobreposta à ética individual e aos interesses particulares. Se a coletividade é superior ao indivíduo, por um artifício lógico que o próprio Aristóteles desenvolveu, o Estado, mandatário da coletividade, tem ascendência sobre qualquer cidadão individualmente. Sob esse prisma, o desígnio primeiro da atividade política seria elucidar a melhor forma de vida que conduza à felicidade, para ulteriormente engendrar a forma de governo e as instituiçôes sociais garantidoras daquela forma de vida à coletividade. Esta última tarefa diz respeito ao estudo da constituição da cidade, donde podemos identificar no corpus aristotélico uma das primeiras incursões sistematizadas no campo do pla-
1 Aristóteles - Vida e Obra. São Paulo: Nova Cultural, 2000. 
2 Aristóteles atribui a Hipódamo de Mileto a invenção da arte de planejar cidades e tece muitas consideracões também acerca dos escritos pioneiros de Platão sobre a matéria, contidos principalmente em Leis e República. No entanto, Aristóteles desfere muitas críticas contra as proposições dos dois pensadores, aponta suas muitas lacunas, e reivindica para si a constituição mais bem estruturada acerca da cidade, em que contempla com pormenores os múltiplos aspectos da vida social, tais como as questões atinentes aos âmbitos jurídico, demográfico, econômico e político, além de discorrer sobre a localização e o traçado urbanístico ideais para a cidade, segundo critérios geomorfológicos e climáticos e também sob o ponto de vista da estratégia militar. No capítulo 4 do livro sétimo de Política, Aristóteles propugna a favor do equilíbrio na constituição demográfico-territorial da cidade. Esta deveria ser suficientemente extensa e populosa para garantir a eficiência e a auto-suficiência econômicas, sem romper o limite que permite adequada coesão social e gestão política: “(...) deve-se então considerar mais perfeita e mais bela a cidade na qual a magnitude é combinada com boa ordem" (Aristóteles, 1997, p.230). nejamento que, uma vez político, versa sobre os domínios da polis, revelando-se, por conseguinte, indissociável e eminentemente espacial.

A cidade, assim como a práxis política, não escapam ao naturalismo aristotélico; ambas seriam decorrências naturais da condição humana enquanto "animal social". Além disso, subjacente a todo esse organismo considerado natural, desvela-se o aspecto coletivista, a ser comungado pelos cidadãos. Nos dizeres do filósofo, "na ordem natural a cidade tem precedência sobre a família e sobre cada um de nós individualmente, pois o todo deve necessariamente ter precedência sobre as partes" (Aristóteles, 1997, p.15).

Logo nos primeiros excertos de Politica, Aristóteles se propõe a decompor essa realidade totalizante que é a cidade, com vistas a deslindar analiticamente seus elementos constituintes fundamentais, o que permitiria compreender os meandros da comunidade política. A cidade é, assim, pioneiramente vista e conceituada como organismo-síntese do sistema sócio-político. Lemos no capítulo 1 do livro primeiro:

Vemos que toda cidade é uma espécie de comunidade, e toda comunidade se forma com vistas a algum bem, pois todas as açôes de todos os homens são praticadas com vistas ao que lhes parece um bem; se todas as comunidades visam a algum bem, é evidente que a mais importante de todas elas, e que inclui todas as outras, tem mais que todas esse objetivo e visa ao mais importante de todos os bens; ela se chama cidade e é a comunidade politica (...) Da mesma forma que em outras matérias é necessário decompor o conjunto até chegar a seus elementos mais simples, com a cidade também, examinando os elementos dos quais ela se compõe, discerniremos melhor, em relação a estas diferentes espécies de mando, qual é a distinção entre elas, e saberemos se é possivel chegar a uma conclusão em bases científicas a propósito de cada afirmação feita pouco antes. (Aristóteles, 1997, p.13)

Infere-se assim que Aristóteles busca aplicar seu método lógico-analítico ao exame dos elementos constituintes da cidade, de sua realidade social, econômica, espacial. Nesses termos, o que o filósofo estagirita faz não é outra coisa senão planejamento. Mais do que isso, faz planejamento de caráter espacial, urbano, ao aduzir sobre a disposição ideal de todo o organismo social assentado na cidade, reconhecendo que os processos sociais estão incrustados no plano espacial, e o espaço da cidade exerce influência sobre a conformação social. Assim, Aristóteles identifica a cidade com a comunidade política e ainda vai além, ao conferir às suas análises e propostas um caráter científico, reclamando para si a edificação de um arcabouço teórico que versa sobre a complexa célula espacial mestra da organização social, qual seja, a cidade. Suas proposições trazem, portanto, o reconhecimento de que o (proto)planejamento envolve ciência e ação política, teoria e prática, prenunciando um porvir sobre o caráter que a matéria virá a assumir nos ulteriores tempos hodiernos. ${ }^{2}$

Essa viagem no tempo e no espaço rumo à Grécia antiga tem tão somente o propósito prosaico de revelar a presença importante que a verve do planejamento teve - ainda que sem essa alcunha e sem o sentido que a ciência moderna lhe conferiu séculos mais tarde - na organização socioespacial das populaçōes humanas desde a antigüidade. A política, segundo Aristóteles, pertence ao grupo da filosofia prática, que busca o conhecimento como um meio para a ação, o que vai ao encontro da concepção moderna de planejamento. A cidade-estado deveria, assim, constituir um aparato institucional cujas práticas ajam na condução da comunidade de cidadãos ao objetivo máximo e sentido último da existência, isto é, à felicidade. O organismo político tem como incumbência planejar a melhor conformação social que permita alcançar esse alvo em sua plenitude. 
No entanto, os meios para atingir os fins da comunidade política são raramente consensuais, o que origina embates num campo de muitas controvérsias. Não obstante o referido planejamento, identificado sinonimicamente com a teoria e a práxis políticas, tenha sido alçado ao status científico, requerendo um caráter de neutralidade e unicidade, os valores morais enraizados e as ideologias sempre teimaram em se fazer presentes, projetando distintas visōes sobre o mundo, refletidas nas diversas correntes de pensamento, proponentes dos mais sortidos diagnósticos acerca da realidade, construídos com base em diversificados métodos, advogando por distintos meios de se alcançar os fins, suscitando muitas controvérsias entre as partes envolvidas no confronto de idéias. E assim foi desde aqueles tempos até os atuais.

Realizando um largo salto temporal, trespassando séculos desde o berço helênico na Idade Antiga até a Idade Moderna, podemos respirar por alguns instantes a atmosfera dos séculos das luzes, ${ }^{3}$ época também marcante e definidora do caráter assumido pela atividade intelectual e pela prática política até hoje vigentes, "fermento de uma transformação técnica e social sem precedentes na história da humanidade. Uma fase de transição, pois, que deixava perplexos os espíritos mais atentos e os fazia refletir sobre os fundamentos da sociedade em que viviam e sobre os impactos das vibraçôes a que eles iam ser sujeitos por via da ordem científica emergente" (Sousa Santos, 2005, p.17). No campo do intelecto e do fazer científico, afirmava-se a primazia da razão sobre ditames míticos ou religiosos. No campo da política, as práticas influentes sobre a constituição social deveriam obedecer aos diagnósticos realizados pela intelligentsia, em geral serviente ao aparato estatal.

O modelo de racionalidade inerente à ciência moderna consolidada no século XVIII, com destacado desenvolvimento das ciências naturais, somente no século $\mathrm{XIX}^{4}$ atingiu cabalmente as ciências sociais - que então sedimentaram alguns princípios epistemológicos e regras metodológicas que caracterizariam as formas de conhecimento social ditas racionais, distinguindo-as do saber medieval -, embora guardasse similaridades com a concepção de ciência fundada no corpus aristotélico, ao qual nos referimos.

A matemática configura-se como o instrumento de análise essencial da ciência moderna, sendo também o próprio modelo ou linguagem de representação dos fenômenos estudados. Uma vez que o conhecer assume como pressuposto o quantificar, o rigor científico passa a ser depreendido da precisão das medições. "As qualidades intrínsecas do objeto são, por assim dizer, desqualificadas, e em seu lugar passam a imperar as quantidades em que eventualmente podem se traduzir. O que não é quantificável é cientificamente irrelevante" (Sousa Santos, 2005, p.28).

O objetivo da ciência moderna pauta-se pelo estabelecimento de relações causais entre fenômenos, com vistas à proposição de leis, pretensamente universais, capazes de descrever regularidades nos fatos naturais e sociais. Nesse contexto, os fatos sociais são tidos como naturais; a ergodicidade própria dos fenômenos físicos é transposta aos fenômenos sociais, fundando uma concepção mecanicista da sociedade. Consubstancia-se, assim, a incorporação da perspectiva positivista às ciências sociais, dando origem a uma "física social” cujo pressuposto básico assevera que as ciências naturais representam a concretização de um modelo de conhecimento universalmente válido.

Todo esse pano de fundo compóe também o cenário em que atuam os teóricos do planejamento. Ao alvorecer do século XIX, quando a ciência social se deixou definitivamente embeber pela lógica própria do cientificismo mecanicista moderno, emergia uma visão segundo a qual os meios para o alcance dos objetivos gerais da sociedade deveriam ser atribuídos a especialistas, dotados da racionalidade científica. Os governantes, investi-
3 A abrangência temporal do lluminismo aqui considerada é compartilhada com aquela definida por Sousa Santos (2005), qual seja, o período compreendido entre meados do século XVII, nascedouro da revolução da física newtoniana, e meados do século XIX, quando a racionalidade iluminista atinge as Ciências Sociais, sendo a economia uma das disciplinas retardatárias nesse processo.

40 atraso e a dificuldade das Ciências Sociais em incorporar tal racionalidade, segundo Kuhn (1962), devese ao seu caráter "précientífico" e à conseqüente ausência de consenso paradigmático. 
5 "(...) should concern themselves primarily with general goals of policy, leaving the choice of the appropriate means to specially trained experts".
6 "Ordinary minds, untrained in the subtleties of the scientific method, were no match for the rationality of those who knew how to make judgements about efficiency in relating means to ends. Parliaments could talk, but the real business of the state would be conducted by men of public spirit and far reaching vision who had received the proper education. Tied to entrepreneurial talent and finance capital, the myriad applications of science would ensure the steady forward march of social progress."

7 Evidente que em uma parte considerável do mundo, principalmente nos países alinhados ao dito socialismo real, já no início do século XX adotavam-se outros critérios para o planejamento centralizado de seu desenvolvimento econômico. No entanto, uma análise das especificidades do bloco de países socialistas foge ao escopo deste trabalho.

8 "(...) the state would plan, the economy would produce, and working people would concentrate on their private agendas: raising families, enriching themselves, and consuming whatever came tumbling out from the cornucopia". dos de poderes políticos, representantes legítimos da população, "deveriam se ocupar dos fins gerais da política, deixando a escolha dos meios apropriados a cargo de especialistas treinados" (Friedmann, 1987, p.4). Sob esses termos, que pavimentam as bases do planejamento moderno, os caminhos a serem seguidos com vistas ao suprimento de demandas da coletividade constituem uma questão essencialmente técnica, que deve obedecer a critérios de eficiência. Assim, aqueles desprovidos da racionalidade científica moderna não estariam aptos a opinar sobre as questóes de interesse geral que visem promover o progresso social.

Mentes comuns, não versadas nas sutilezas do método científico, não estavam à altura da racionalidade daqueles que sabem como fazer julgamentos sobre eficiência na relação entre meios e fins. Parlamentos podiam conversar, mas o real negócio do Estado seria conduzido por pessoas dotadas de espirito público e visão de longo alcance, que receberam o treinamento adequado. Associada ao talento empresarial e às finanças, a miriade de aplicaçôes da ciência garantiria a marcha firme rumo ao progresso social. ${ }^{6}$ (Friedmann, 1987, p.5)

Planejar, enfim, assumia peremptoriamente o caráter de uma empreitada científica e de viés economicista. No tocante aos aspectos econômicos do planejamento - campo primaz da ação política em sociedades capitalistas modernas - , as regras hegemônicas passavam a ser ditadas por uma vertente liberal que retomava os princípios subjacentes às teorias clássicas de autores como Adam Smith e David Ricardo, recheando-os com a racionalidade positivista em ascensão nas ciências sociais durante o século XIX. O conceito econômico de eficiência seria o balizador das decisóes a serem tomadas pelas instâncias de planejamento.

Essa toada liberal foi a tônica vigente na transição do século XIX ao século XX, ${ }^{7}$ que claramente se refletia e se sustentava no ideário do planejamento, embotado pela racionalidade positivista que edificava "um conhecimento causal que aspira à formulação de leis" (Sousa Santos, 2005, p.29). A identificação da causa formal de um fenômeno social permitiria a realização de predições, uma vez que a ergodicidade, fundada na idéia de ordem e estabilidade do mundo, configurava o pressuposto metateórico que regia o fazer científico. Tais predições seriam, em última instância, o instrumento balizador do planejamento, que permitiria manipular e transformar a sociedade, de forma similar à que os cientistas naturais se valem para dominar a natureza. "Tal como foi possível descobrir as leis da natureza, seria igualmente possível descobrir as leis da sociedade" (Sousa Santos, 2005, p.32). No tocante aos aspectos da reprodução material da sociedade, a lei social basilar que então presidia os fenômenos econômicos era o mecanismo smithiano de interação entre oferta e demanda, acrescido da tendência ao equilíbrio geral aventado por Leon Walras (1996). A racionalidade de mercado, que supostamente norteia o comportamento dos agentes econômicos, asseguraria uma tendência estrutural e inexorável do sistema econômico-social ao equilíbrio.

A divisão do trabalho social, que Smith (1996) teoriza como sendo a fonte primaz do aprimoramento das forças produtivas e motor do crescimento econômico e do progresso social, se daria conforme o seguinte trâmite: "o Estado planejaria, a economia produziria e a população de trabalhadores se concentraria em suas agendas privadas: formar famílias, enriquecer-se e consumir o que sua riqueza puder comprar"8 (Friedmann, 1987, p.8). Esta é a ordem de coisas que rege a sociedade liberal, amparada em um "guia social" que mescla o naturalismo e o individualismo como princípios filosóficos da ciên- 
cia que fundamenta o planejamento de caráter positivista vigente no início do século XX, e que retorna fortalecido em fins do mesmo século, após um interregno mais intervencionista e socialmente agitado em seus meados.

A idéia de que o mercado, formado por agentes econômicos auto-interessados, deixados à sua própria sorte, conduz a um estado de equilíbrio eficiente e a um resultado social agregado positivo, é dificilmente corroborada pela realidade. No entanto, a assunção dessa racionalidade de mercado impera sobre as teorias economicistas de planejamento. Paradoxalmente, a exacerbação dessa perspectiva findou por fazer do planejamento, no ocaso do século XX, uma prática dispensável, uma vez que o comportamento auto-interessado dos indivíduos conduziria a um resultado social desejado, independentemente de esforços conscientes de planejamento ou coordenação entre os agentes econômicos.

Como já mencionado, é forçoso reconhecer que o planejamento guarda uma relação orgânica com os requisitos da prática política, procura voltar o conhecimento para a ação, seja no sentido de transformar, seja no sentido de controlar a sociedade e as relaçóes que lhe subjazem. Entremeadas nesse palco assaz conflituoso, atuam algumas perspectivas teórico-metodológicas e/ou práticas que se abrigaram em algumas importantes tradições de pensamento sobre o planejamento, dentre as quais podem-se citar, seguindo a tipologia aduzida por Friedmann (1987), a "reforma social" (social reform) e a "análise de políticas" (policy analysis), que se impuseram hegemonicamente no capitalismo urbano-industrial moderno, quer sob a forma de um arcabouço teórico-conceitual de natureza científica, quer sob a forma de proposições políticas de controle social. A tradição dominante, que concebia o planejamento como reforma social, referenciava-se numa matriz de pensamento positivista comteana (e saint-simoniana), ${ }^{9}$ segundo a qual a "ciência da sociedade" guiaria o mundo por uma trajetória de progresso social. O planejamento serviria, pois, a um processo de guia ou direcionamento social (societal guidance) ${ }^{10}$ rumo ao progresso; este concebido sob um viés tecnicista.

\section{Reforma Social e AnÁlise de Políticas: ${ }^{11}$ DUAS TRAdiçóes E uma só DOUTRina}

A lógica que permeia o modus operandi do capitalismo industrial, assim como a teoria econômica (neo)clássica que procura explicar tal sistema (e em certa medida o legitimar), estão assentadas na assunção de busca da eficiência econômica stricto sensu, adutora de uma racionalidade que pressupóe o compromisso individual com um comportamento auto-interessado, que se desdobraria em um resultado social agregado compatível com os interesses da coletividade. Evidencia-se, assim, uma perspectiva argumentativa ajustada à doutrina smithiana da harmonia natural de interesses, cujo mote clássico traz a idéia de que "vícios privados resultam em benefícios públicos" (private vices yield public benefit). Nesses termos, identificamos na teoria econômica clássica de Smith a perspectiva naturalista cara ao antigo discurso aristotélico, porém desprovida do aspecto coletivista próprio deste. $\mathrm{O}$ aspecto coletivista perde sua primazia para o individualismo associado à racionalidade de mercado (market rationality).

Ao contrário da visão aristotélica supra, a doutrina individualista propugna a ascendência lógica do indivíduo sobre a sociedade, donde decorre que a razão deva ser exercida em nome do indivíduo, sendo que a satisfação das necessidades materiais individuais passa a ser a principal razão da vida das pessoas em grupos sociais. Nesses termos, a vida em grupo é válida enquanto potencializadora da divisão social do trabalho, que propicia
9 Claude Henri de Rouvroy, o Conde de Saint-Simon, é identificado com o socialismo utópico francês. Autor de obras importantes e defensor da primazia de uma racionalidade tecnicista a ser imposta sobre a sociedade, prognosticou a emergência de uma sociedade industrial na Europa e contribuiu para a constituicão de todo um ideal da modernidade, além de ser um precursor da filosofia positivista.

10 Cumpre considerar que a carga semântica inerente aos termos "guia" e "direcionamento", derivados do termo em inglês "guidance", assume aqui um sentido de aconselhamento, além de manipulação e/ou controle.

110 leitor perceberá que tratamos as correntes reforma social e análise de políticas de forma quase indistinta. Isto porque concebemos a análise de políticas como um desdobramento direto da reforma social, em razão da similitude das premissas e objetivos de ambas as vertentes, assim como a afinidade de sua filiação filosófica e da linguagem utilizada em seus discursos científicos. Devemos, no entanto, reconhecer que há dessemelhanças, sendo que os autores identificados com cada uma das tradições não formam um bloco monolítico. Consideramos, todavia, que esse tratamento genérico não compromete os argumentos. 
12 "(...) production and livelihood depend largely on market rationality, but unrestrained profit making destroys the bonds of human reciprocity that lie at the foundation of all social life". o desenvolvimento das forças produtivas e permite maior oferta de bens e serviços que atenderão às necessidades do bem-estar de cada indivíduo.

No entanto, as forças cegas embutidas na racionalidade de mercado historicamente geraram muitos resultados sociais nefastos, tais como desemprego, pobreza urbana e altos graus de desigualdade de riqueza. Revelava-se necessário, pois, contrapor aos mecanismos de mercado uma racionalidade social, consoante à qual a razão seria exercida com vistas a dirimir os resultados indesejáveis oriundos do comportamento auto-interessado de indivíduos e corporaçóes, ou seja, da racionalidade de mercado. Isto porque o modo de produção capitalista é um sistema contraditório, em que "a produção e a sobrevivência dependem em grande medida da racionalidade de mercado, mas a busca irrestrita do lucro destrói os laços da reciprocidade humana que estão na base de toda a vida social" 12 (Friedmann, 1987, p.29).

Nesse sentido, o Estado assume um papel de mediador de conflitos entre os interesses individuais e sociais. Enquanto expressão da totalidade da comunidade política, o Estado desempenha um papel ambivalente, que deve a um só tempo encorajar e potencializar os interesses de expansão do capital, e evitar que uma eventual exacerbação desses interesses provoque efeitos nocivos sobre o tecido social. A administração desses conflitos passa a ser a atribuição fundamental que cabe ao planejamento em sociedades de mercado.

Para se concretizar enquanto agente de reforma social, o planejamento precisou se amparar em uma noção de racionalidade social que pudesse nortear o processo de "societal guidance". Com vistas a catalisar uma reforma social, o planejador deveria munirse de uma capacidade de predizer o futuro com razoável grau de precisão, capacidade essa que é supostamente provida pelos modelos mecanicistas da "física social". Para ser efetivo, o planejamento deveria proceder a uma dinâmica de "societal guidance" que fizesse convergir as ações individuais conforme as leis sociais "naturais" (de mercado), simultaneamente à adoção de medidas corretivas sobre as "falhas" de mercado. Este último procedimento é, no mais das vezes, a única ação afirmativa no processo de reversão dos efeitos nocivos da economia de livre mercado.

Nesse sentido, em uma sociedade de mercado, muitos dos "usos" a que se presta o planejamento, embora levados a efeito em nome de uma racionalidade social, acabam por se identificar paradoxalmente com os princípios de mercado, na medida em que se enfeixa a garantir a realização de lucros por parte de negócios privados individuais, fonte da sobrevivência da maior parte das pessoas inseridas emuma sociedade capitalista.

Dessa forma, encontram-se entre as atribuições do Estado-planejador as diretrizes gerais da economia, que incluem desde a provisão de serviços públicos - que muitas vezes significa parte dos custos de reprodução da força de trabalho - até investimentos em infra-estrutura, passando por políticas macroeconômicas de incentivo ao crescimento e conformação de um aparato jurídico-regulatório garantidor dos direitos de propriedade. Sob esse prisma, a ingerência do órgão planejador sobre algumas atividades, tais como provisão de serviços públicos de educação, saúde ou infra-estrutura urbana, embora apareça geralmente sob a alcunha de investimentos sociais - e portanto revestidos de uma racionalidade social -, constitui, com efeito, o atendimento às necessidades de aceleração do processo de rotação do capital. Embora não constituam setores diretamente produtores de lucros, configuram meios de consumo coletivo e meios de circulação material que impulsionam as engrenagens capitalistas, favorecendo indiretamente a reprodução do capital. Assim, a organização social capitalista permite uma (con)fusão entre interesses individuais e sociais. 
Evidente que a concepção de planejamento consubstanciada na reforma social, que traz à tona a idéia de racionalidade social, guarda em si alguns propósitos de constranger a operação das forças de mercado. No entanto, seu regime fundamental de societal guidance visa essencialmente à manutenção da ordem social capitalista, donde a garantia de direitos individuais ganha preeminência, ainda que esse discurso seja muitas vezes proferido em nome da coletividade.

Adutora de uma visão de planejamento fundada em uma razão técnica, a corrente da reforma social em larga medida incorporou aspectos defendidos pela corrente identificada por Friedmann (1987) como "análise de políticas". Esta última vertente, que pode ser considerada o ressurgimento fortalecido da reforma social em meados do século XX, sob uma nova roupagem, propugna que as soluçōes para os objetos sociais do planejamento derivam de uma análise "científica" de dados. O tratamento dos dados coletados por investigadores sociais seriam porta-vozes da realidade empírica e forneceriam subsídios para a elaboração de planos de intervenção no domínio público. A relação de complementaridade estabelecida entre reforma social e análise de políticas representa, pois, a síntese do planejamento moderno em sociedades de mercado.

Segundo os argumentos incutidos nessa síntese, o mundo é passível de apreensão objetiva a partir dos instrumentos da ciência positivista; e o objetivo do planejamento moderno consiste em tornar o conhecimento técnico e científico útil às ações de direcionamento social. Assentado nas idéias comteanas e saint-simonianas segundo as quais o corpo social é regido por leis mecânicas e orgânicas, o planejamento economicista moderno argumenta que a sociedade está apta a administrar seu destino quando apresenta habilidade para predizer resultados futuros de fenômenos ou ações presentes. August Comte escreve em seu Plan of Scientific Works Necessary for the Reorganization of Society (Plano de Trabalho Científico Necessário para a Reorganização da Sociedade):

\begin{abstract}
Não pode pairar nenhuma dívida de que o estudo da natureza realizado pelo homem deve fornecer a única base de sua ação sobre a natureza; e, portanto, somente conhecendo as leis que regem os fenômenos e, por conseguinte, estando apto a predizê-los, é que nós podemos, na vida efetiva, ajustá-los e modificá-los em nosso beneficio (...) A relação entre ciência e prática pode ser resumida em uma curta expressão: da ciência deriva a previsão; da previsão deriva a ação. ${ }^{13}$ (Comte, 1822 apud Lenzer, 1975, p.88)
\end{abstract}

Esta é a linha mestra pela qual se guiam a ciência e o planejamento na modernidade; aquela estabelecendo relações causais imutáveis e unidirecionais entre fenômenos sociais, este levando a efeito açôes de societal guidance. "É objeto da ciência estabelecer fatos e leis imutáveis. Ao planejador é deixada a tarefa de guiar o curso do progresso social conforme tais leis" ${ }^{14}$ (Friedmann, 1987, p.71). O planejamento assentado no binômio "reforma social-análise de políticas" ambicionava moldar a sociedade a partir da obediência às leis naturais. Assim como os corpos em queda livre se submetem à lei da gravidade, a sociedade sucumbe às leis sociais naturais e cientificamente enunciadas. O planejador teria à sua disposição um sistema analítico que descreve a mecânica social, "baseado na conceitualização científica e na pesquisa empírica, através das quais poderia predizer que tipo de instituiçóes e processos a sociedade industrial emergente iria requerer" $^{15}$ (Ionescu, 1976, p.7).

No processo de societal guidance, o papel do Estado é manter sob sua tutela o poder de orientação da sociedade, conduzindo-a conforme os ditames das leis sociais sacramen-
13 "There can be no doubt that man's study of nature must furnish the only basis of his actions upon nature; for it is only by knowing the laws of phenomena and thus being able to foresee them, that we can, in active life, set them to modify one another to our advantage (...) The relation of science to art may be summed up in a brief expression: from science comes prevision; from prevision comes action".

14 "It is the business of science to establish facts and immutable laws. For planner is left the task of guiding the course of social progress in accordance with these laws".

15 “(...) based on scientific conceptualization and empirical research, and through which he could predict what kind of institutions and processes the emerging industrial society would require". 
16 "The formation of any plan for social organization necessarily embraces two series of works as distinct in their objects as in the intellectual efforts they demand. One, theoretical or spiritual, aims at developing the leading conception of the plan - that is to say, the new principle destined to coordinate social relations - and at forming the system of general ideas, fitted to guide society. The other, practical or temporal, decides upon the distribution of authority and the combination of administative institutions best adapted to the spirit of the system already determined by the intellectual labors".
17 "The reliance of policy analysts on the tools of neoclassical economics implies that the value premises of that discipline are built into their work; chief among these values are individualism, the supremacy of the market in the allocation of resources, and the inherent conservantism of the equilibrium paradigm. Because market outcomes are regarded as 'rational' for the actors involved, deviations from them are normally thought to require special justification and are admitted only reluctantly". tadas pelo paradigma científico hegemônico. O planejamento é uma empreitada científica, seguidor fiel do cânone positivista comteano:

A formulação de qualquer plano de organização social necessariamente envolve duas frentes de trabalho distintas, tanto no tocante aos seus objetos quanto no que tange aos esforços intelectuais demandados. Uma delas, de natureza teórica ou espiritual, visa desenvolver a concepção inicial do plano - isto é, o novo princípio destinado a coordenar as relaçôes sociais - e formar o sistema de idéias gerais adequadas para guiar a sociedade. A outra, de ordem prática ou temporal, decide sobre a delegação de autoridade e sobre o conjunto de instituiçôes melhor adaptado ao espirito do sistema previamente determinado pelos trabalhos intelectuais. ${ }^{16}$ (Comte, 1822 apud Lenzer, 1975, p.19)

A tradição da análise de políticas, aqui tratada como desdobramento direto da reforma social, em virtude de sua filiação aos mesmos paradigmas científicos e políticos, veio a acrescentar elementos ao corpo do planejamento, elementos esses que, fundidos aos princípios social-reformistas, sintetizam a essência do planejamento na modernidade. Originalmente, os estudos da policy analysis se voltavam para as tomadas de decisões microeconômicas de firmas e corporaçôes, sendo suas construções teóricas posteriormente generalizadas. Esta abordagem tinha por objetivo identificar os melhores cursos de ação dentre algumas possibilidades e condiçóes iniciais dadas. Para tanto, dever-se-ia empregar a habilidade em realizar escolhas "racionais", que lancem mão do maior número possível de informações disponíveis e calcule de maneira eficiente os custos e benefícios de cada trajetória possível. Os autores identificados com essa tradição se auto-proclamam tecnocratas, típicos "engenheiros sociais" à la Saint-Simon ou à la Comte. Crêem-se capazes, através de modelos matemáticos e técnicas estatísticas, de identificar e calcular precisamente as melhores soluçôes para os dilemas sócio-econômicos.

A reforma social e a análise de políticas representam o triunfo da razão economicista e caracterizam-se, ao fim e ao cabo, por um conservantismo em relação ao estado de coisas. A idéia que habita o seio dessa visão de mundo passa pela pretensão de extirpar do planejamento todo o conteúdo ideológico ou passional, preservando tão somente a pureza do teor científico, capaz de descrever as leis que regem a sociedade e assegurar seu funcionamento de maneira a mais desimpedida. Ao planejamento moderno, sob a batuta dessa corrente de pensamento e ação, cabia promover a extensão das relações sociais de produção capitalistas urbano-industriais, legitimando a racionalidade de mercado.

A confiança dos analistas de politicas no ferramental da economia neoclássica implica que os valores e as premissas dessa corrente estão embutidas em seus trabalhos; dentre tais valores destacamse o individualismo, a supremacia do mercado na alocação de recursos, e o conservadorismo inerente ao paradigma do equilíbrio. Dado que os resultados de mercado são considerados "racionais" pelos atores envolvidos, discrepâncias em relação a tais resultados requerem justificativas e só são admitidas com relutância. ${ }^{17}$ (Friedmann, 1987, p.79)

Não é preciso mais do que uma olhadela ao redor e um bocado de senso comum para constatar que a empreitada do planejamento na modernidade, se tinha o propósito de colocar a ciência a serviço do bem público, não obteve êxito. Essa perspectiva do planejamento moderno em sociedades de mercado acabou por se identificar com uma lógica conservadora de manutenção do status quo, revelando-se no máximo comprometida com 
mudanças evolucionárias modestas próprias do capitalismo, negando a possibilidade de transformações estruturais que revertam o processo de exclusão social típicas do modo de produção hegemônico. A reforma social e a análise de políticas devotam seus esforços ao aprimoramento do capitalismo, um sistema de produção e reprodução sociais que, na visão dessas correntes de pensamento, incorre em falhas mas é passível de aperfeiçoamentos; sendo considerado o modo de organização social mais avançado do qual a humanidade pode dispor. Buscavam, destarte, instalar e manter a ordem social burguesa. Valendo-se do economicismo, que busca a descrição do organismo social por meio da construção de modelos expressos em termos universais - cujas hipóteses simplificadoras negam eventuais particularidades históricas, institucionais ou estruturais, tratadas tão somente como "falhas" de mercado a serem corrigidas - , o planejamento moderno padece de uma incompletude no tocante a sua descrição de realidades específicas, seja pelo afã de se autoproclamar "científico" e explicar a sociedade por um discurso objetivo, seja como arauto de uma ingerência mínima do Estado na mecânica social, contraditoriamente extirpando do planejamento sua compleição enquanto meio concreto de ação transformadora no domínio público.

Do que vimos, temos em mãos um breve relato da forma assumida pelo planejamento na modernidade, umbilicalmente ligado às concepções da ciência positiva e da razão tecnicista e economicista que povoa o imaginário do homem moderno. Reconhecendo que o planejamento define-se pela relação complementar e dialética entre teoria e prática, conhecimento e ação, ciência e política; e considerando ainda o caráter naturalista, mecanicista e positivista assumido pelo planejamento moderno como reflexo dos matizes científicos, duas tarefas se interpõem aos propósitos do nosso trabalho: primeiro, enfatizar uma visão espacial, partindo da concepção segundo a qual as sociedades são organismos espacialmente referenciados, a um só tempo indagando e buscando responder qual o papel reservado ao espaço nas teorias do planejamento e do desenvolvimento. Segundo, sabendo que o planejamento é depositário de uma visão sobre o mundo, cumpre retomar a crítica às perspectivas epistemológicas tipicamente modernas (e ainda aceitas contemporaneamente), sugerindo passos na direção de uma agenda alternativa, que olhe o mundo não somente enquanto instrumento analítico para entender racionalmente a realidade social, mas também enquanto projeto teórico-político, capaz de engendrar uma construção crítica e propositiva emancipatória. É sobre estas questóes que nos debruçamos nas seções seguintes.

\section{O PAPEL DO ESPAÇO NA TEORIA DO PLANEJAMENTO}

Embora presente desde os primeiros excertos, o espaço não mereceu ainda neste texto o devido cuidado. Mencionamos en passant o fato de que o planejamento, já nos seus prolegômenos durante a Idade Antiga, conferia ao contexto espacial um tratamento privilegiado no corpo das teorias e filosofias sociais. Isto porque os pensadores da antigüidade tinham a cidade e sua complexidade como expressão máxima e genuína da comunidade política, objeto da filosofia política e social. As teorias, os métodos e os instrumentos do pensar e do agir sobre a sociedade estão intrínseca e dialeticamente correlacionados ao conhecimento e à atuação política sobre a configuração espacial. Assim, as cidades, as regiōes e as outras múltiplas escalas espaciais das quais a sociedade participa como tecido vi- 
18 "As a consequence, any idea of development outside of neoliberal capitalism is prohibited, as well as any independency of development theory as a discipline distinct from the dominant neoclassical corpus".

19 " (...) there is a standart model of behavior applicable in all times and places. (...) Heavily mathematical, strongly normative, and reliant upon a host of absurdly unrealistic assumptions, general equilibrium theory is the keystone of all standard microeconomics". tal, e nas quais os grupos humanos organizam sua reprodução social, são, por princípio, objeto do planejamento.

Dessa forma, o planejamento deve incutir como ponto de partida a noção de que seu objeto é um sistema de relaçóes sociais espacialmente referenciado. A geografia da organização social assume papel ativo na dinâmica dos processos sociais, porquanto devem figurar como aspecto de suma relevância na construção do conhecimento que informa o planejamento no domínio público (Friedmann \& Weaver, 1979; Friedmann, 1987). Ultrapassando a perspectiva vigente na modernidade, Soja (1993) preconiza por "espacializar" criticamente a realidade social, deslindando-a de forma mais reveladora, erigindo um arcabouço mais abrangente e incisivo não apenas para a apreensão racional dos fenômenos socioespaciais, mas também para a fundação de práticas emancipatórias.

Não obstante, a tomada das ciências sociais pela perspectiva epistemológica do positivismo teve como desdobramentos, na teoria econômica, as construções teóricas neoclássicas fundadas no individualismo metodológico e nas premissas de otimização e equilíbrio geral. No campo político, o mecanicismo desses modelos teóricos legitimou o liberalismo e mais recentemente sua "neo-roupagem", que apostam nos mercados como mecanismo coordenador da reprodução material das sociedades humanas; mecanismo esse que idealmente garantiria uma convergência inexorável dos padróes de vida e níveis de desenvolvimento interregionais, muitas vezes ignorando as "rugosidades" espaciais que impõem atritos à disseminação da modernização tecnológica e do crescimento econômico pelos territórios em sua totalidade. O ideário hegemônico da modernidade, no desiderato de transitar de uma economia política para uma economia pura, reduzia ao mínimo qualquer intervencionismo deliberado de instituições extra-mercado, ferindo de morte o planejamento e condenando as políticas de desenvolvimento regional ao fenecimento. "Por consequência, qualquer idéia de desenvolvimento fora do capitalismo neoliberal é proibida, assim como também o é qualquer independência da teoria do desenvolvimento enquanto disciplina destoante do corpus neoclássico dominante" 18 (Herrera, 2006, p.5). Adita-se a isso o fato de que tais construções teóricas tendem, via hipóteses simplificadoras que calçam sua argumentação, a homogeneizar contextos, o que traz como corolário a secundarização ou mesmo exclusão do espaço enquanto variável de análise. Ao adotar premissas de homogeneidade, a teoria econômica convencional acabou por conferir ao espaço um papel adiáforo, uma vez que supostamente "há um modelo padrão de comportamento aplicável em todos os tempos e lugares. (...) Profundamente matematizada, fortemente normativa e dependente de uma série de suposiçóes irrealistas, a teoria do equilíbrio geral é a base de toda a microeconomia convencional"19 (Herrera, 2006, p.8). Em grande medida, essa perspectiva esvaziada do elemento espacial pode ser também explicada pelo fato de que seus formuladores, em geral cidadãos de países centrais, pensam uma realidade com grau relativamente baixo de heterogeneidade, mais próxima de uma configuração "clean space". Essa concepção, segundo Soja (1993), mostra-se pouco atenta "à espacialidade formadora da vida social como padrão de discernimento crítico"; e a variável espaço comparece (quando comparece) travestida em custos de transporte de mercadorias a serem minimizados pelos agentes econômicos com vistas à localização ótima da firma ou à alocação eficiente de recursos.

A reflexão geralmente situa os atores num espaço sem relevo nem densidade, onde os obstáculos são identificáveis por um sistema de custos (...) Esta visão das coisas aparece em perfeita consonância 
com a interpretação walrasiana da coordenação econômica do mercado, fundado sobre a média e a homogeneidade, na medida em que a introdução do espaço não faz mais do que completar a formação dos custos e, por conseguinte, por meio dos comportamentos de localização, o programa otimizador dos agentes. (Pecqueur e Zimmermann, 2005, p.77-8)

$\mathrm{Na}$ economia política, o exercício de imaginação geográfica, mesmo quando não era limitado analiticamente, permanecia marginal no corpus teórico geral. A percepção teórica implícita nos argumentos espaciais seminais, levados a efeitos por pensadores identificados com a economia política, ou circunscreveu-se ao status categórico de um insight poderoso porém pouco "desenvolvido" (formalizado), como à idéia de vantagens locacionais (pecuniárias e tecnológicas) aduzida por Alfred Marshall; ou estavam alçados ao status de conceito teórico sintetizador porém marginal no arcabouço dos economistas, donde os elementos espaciais sempre tiveram sua importância sistematicamente negligenciada. Neste último caso incluímos com destaque duas formulações: a idéia de renda fundiária de J. H. Von Thünen, argumento-síntese da lógica locacional e indispensável ao entendimento da dinâmica urbano-regional; e a "Lei Espacial da Demanda" enfeixada por August Lösch, teoria espacial de caráter economicista, adutora da idéia de área de mercado. O que importa reter é que, no campo de uma economia que renegava gradativamente o adjetivo "política", o espaço não era incorporado senão através da "força física 'neutrà da fricção de distância”, expressa de forma metafórica (ou, se quisermos, fetichizada e reificada) em custos de localização e custos de transporte.

Alternativamente, algumas vertentes de teorias econômicas e sociais que têm o espaço como categoria privilegiada de análise reconhecem a complexidade da configuração espacial e sua relação dialética com os processos sociais, e recusam assim uma teleologia simplificada em suas formulações. Destarte, os autores identificados com essa perspectiva revelam-se ciosos por uma olhar crítico que engendre uma "economia política da produção social do espaço", e não somente uma descrição de processos econômico-espaciais por meio de estruturas lógicas e unidirecionais de causa e efeito.

\section{RUMO AO PLANEJAMENTO SOCIOESPACIAL CRÍTICO}

Segundo Lefebvre $(1991,1999)$ e Soja $(1993)$, as teorias sociais fundadas na racionalidade mecanicista típica da modernidade padecem de uma "ilusão de opacidade" no tocante ao tratamento do espaço e acabam por obnubilar a imbricação dialética entre a espacialidade concreta e as relações sociais imersas nessa espacialidade. O espaço opaco é um lugar "sombrio e fechado", que não se permite ser enxergado em todas as suas nuances. É uma materialidade espacial reificada, vista pelo prisma dos universalismos abstratos característicos da ciência moderna - lente pela qual as teorias econômico-espaciais de cunho neoclássico enxergam o mundo. Edward Soja adverte que essa lente, em vez de corrigir, clarificar e ampliar o campo de visão, induz "a uma miopia que enxerga apenas uma materialidade superficial, formas concretizadas que são passíveis de pouco mais do que a mensuração e a descrição fenomênica: fixas, mortas e não-dialéticas - a cartografia cartesiana da ciência espacial" (Soja, 1993, p.14). Edward Soja herda de Henri Lefebvre a sensibilidade de que, no capitalismo contemporâneo, o espaço é a categoria analítica privilegiada para entender a realidade social. Pela dialética lefebvreana, sintetizada no conceito de "espaço social", o espaço transfunde-se na própria realidade social. Simultaneamente o espaço é um produto social e também tem vida própria, adquirindo, em uma 
20 "(Social) space is a (social) product. This proposition might appear to border on the tautologous, and hence on the obvious. There is good reason, however, to examine it carefully, to consider its implications and consequences (...) Many people will find it hard to endorse the notion that space has taken on, within the present mode of production, within a society as it actually is, a sort of reality of its own, a reality clearly distinct from, yet much like, those assumed in the same global process by commodities, money and capital".

21 "We have already been led to the conclusion that any space implies, contains and dissimulates social relationships".

22 Henri Lefebvre rejeita 0 termo "planejamento", preferindo utilizar a noção de "projeto" como substituto, este definido como uma "intervenção estratégica que supera o relativismo da filosofia através do cálculo político", sempre deixando explícita a concepcão dialética segundo a qual o possível (o virtual) integra e molda 0 presente (o real). Considerando que a negação do uso do termo "planejamento" mais significa uma negação à feição assumida por essa atividade na modernidade, levamos adiante o uso do termo em nosso trabalho com mesma carga semântica do "projeto" lefebvreano. Assim, usamos os termos "projeto" e "planejamento" indistintamente, como sinônimos.

23 "I shall demonstrate the active role of space, as knowledge and action, in the existing mode of production".

24 Em A Revolução Urbana, Henri Lefebvre delineia um processo heurístico para a definição (ou descoberta) do urbano substantivo, visto visão global do sistema, o mesmo caráter de elementos como a mercadoria e o próprio capital, vistos enquanto categorias que ocultam em si as relações sociais de exploração e apropriação do mais-valor que é a razão de ser do sistema:

O espaço (social) é um produto (social). Esta proposiçāo pode parecer redundante, tautológica, e portanto óbvia. No entanto, há boas razôes para examiná-la cuidadosamente e considerar suas implicações e conseqüências (...) Muitas pessoas acharão dificil defender a idéia de que o espaço assumiu, no presente modo de produção, em uma sociedade como a atual, uma espécie de condição própria, uma realidade claramente distinta, ainda que muito similar, àquela assumida, no mesmo processo global, pelas mercadorias, pelo dinheiro e pelo capital. ${ }^{20}$ (Lefebvre, 1991, p.26)

Fomos levados à conclusão de que todo espaço implica, contém e oculta relaçōes sociais. ${ }^{21}$ (idem, p.83)

"Localizar" o espaço no primeiro plano da investigação social torna-se então a tarefa a que se propõe Henri Lefebvre, de forma a sistematizar um planejamento (ou projeto $)^{22}$ teórico e prático aplicável à configuração socioespacial do capitalismo contemporâneo, e que contenha um teor crítico e politicamente emancipatório.

Teóricos convencionais concebem o espaço tão somente como um receptáculo; seguem uma linha que "afirma serem os processos sociais desenvolvidos no espaço, de forma que o espaço apenas os mantém ou suporta” (Gottdiener, 1993, p.125). Remando contra essa corrente, Lefebvre (1991, p.11) chama para si a tarefa de desfazer a reificação espacial em que incorrem esses teóricos: "Devo demonstrar o papel ativo do espaço, como conhecimento e ação, no presente modo de produção" ${ }^{23}$ Logo, o espaço traz a economia (modo de produção) e suas relações sociais subjacentes como elementos de fundamental importância para sua compreensão. A reprodução das relações sociais que sustêm o sistema capitalista é condicionada por efeitos da aglomeração urbana, donde constatamos que a evolução e perpetuação do sistema, mormente em seu estágio contemporâneo mais avançado, realiza-se através de formas espaciais, ou mais propriamente de um contexto socioespacial:

(...) o capitalismo como totalidade é um projeto histórico inacabado. Como modo de produção, mudou e alterou-se a fim de sobreviver. Lefebvre concebe a sobrevivencia do capitalismo como uma conseqüência de sua capacidade de recriar todas as relaçôes sociais necessárias para o modo de produção numa base contínua. Isso foi conseguido, no decurso dos anos, pelo uso do espaço pelo capitalismo. (Gottdiener, 1993, p.147)

Foi em seu livro The Survival of Capitalism que Lefebvre (1976) enunciou essa que talvez seja sua afirmação teórica mais vigorosa no que concerne à colocação do espaço como elemento central na teoria social: foi por meio de um processo de espacialização, de produção de um espaço conformado à sua lógica de reprodução, que o capitalismo descobriu-se capaz de atenuar suas contradições internas e sobreviver. O complexo socioespacial fundido conceitualmente na idéia do urbano (substantivo ${ }^{24}$ ) traz embutida a noção de que a dimensão espacial, ao favorecer a reprodução das relações sociais de produção, permitiu a sobrevivência e o crescimento do capitalismo. O urbano "se apresenta, desse modo, como realidade global (ou, se se quer assim falar: total), implicando o 
conjunto da prática social" (Lefebvre, 1999, p.53). Trata-se de uma "revolução urbana" adutora de uma espacialidade que se estendeu "fagocitando" a realidade social e incutindo-lhe sua lógica; lógica da qual o capitalismo se apropriou e colocou sob sua égide a fim de se reproduzir.

Esboçando pensamento similar, Edward Soja deriva do urbano lefebvreano o conceito de urbanismo, que diz respeito à espacialidade específica que o capitalismo cria e póe a serviço da valorização do capital, de sua reprodução ampliada e da aceleração do ciclo do capital-dinheiro. Nessa perspectiva, o espaço ganha status funcional similar ao dos elementos protagonistas do capitalismo, como a mercadoria ou o próprio capital. Da mesma forma que a mercadoria e o capital constituem "entidades" que ocultam em si as relações sociais de produção, o urbanismo seria a conceituação sumária da relação dialética entre o modo capitalista de produção e sua espacialidade socialmente criada.

De forma complementar à formulação sojiana, David Harvey (1973, 1975, 1977, 1992) argumenta que o espaço urbano é alvo de sucessivas construções, desconstruções e reconstruções, com vistas a moldar-se pelas conveniências da reprodução do capital. Para ele, a forma urbana cristalizada no ambiente construído (the spatial " $f i x$ ") é a expressão material do capital, constituindo uma paisagem física funcional à acumulação. Harvey salienta ainda a necessidade de ver o ambiente urbano como lugar privilegiado não só da produção industrial, mas também do consumo; como sítio da produção de mercadorias e também da circulação e "realização" destas. Como afirmava Karl Marx, a criação do valor é caracterizada quando do processo de valorização ocorrido paralelamente ao processo de trabalho na fábrica, no momento em que a mais-valia é extraída da força de trabalho e incorporada na mercadoria produzida. Entretanto, até esse momento, não foi criado mais do que um valor em potencial, que somente será efetivamente "realizado" pela "socialização" da mercadoria, consubstanciada pela sua venda (consumo). Assim, Harvey traz a percepção de que o centro urbano é o lugar concentrador da demanda e, portanto, espaço da realização da mais-valia e da reprodução sistêmica do capitalismo. Além disso, está contido nessa percepção um diagnóstico da dinâmica urbano-regional, vinculada à dupla dependência do capitalismo em relação à concentração e à desconcentração espacial da apropriação de mais-valia. Os núcleos de produção e os contextos regionais que os circundam são ambos importantes na medida em que o capitalismo depende, primeiramente, da concentração e depois da circulação do sobreproduto gerado na cidade. Erige-se, pois, no centro urbano e sua articulação regional, um sistema socioespacial auto-contido para acumulação de capital, na medida em que abrange todo o espectro do processo capitalista (produção, circulação e consumo), contemplando assim todo o ciclo do capitaldinheiro (D-M-M'-D'), desde a produção de mercadorias até a realização do mais-valor via consumo nos mercados. A contribuição de David Harvey, portanto, passa pela concepção do espaço urbano como uma "máquina” produtora e apropriadora de mais-valia, donde o urbano constitui a espacialidade ideal, o habitat do sistema capitalista.

Formado pelo estruturalismo althusseriano, Manuel Castells (1977, 1999), por seu turno, também concebe o espaço urbano como núcleo serviente à dinâmica capitalista, porém enfatizando seu papel como locus da reprodução da força de trabalho. Por esse prisma, o núcleo urbano significa a aglomeração de um aparelho infra-estrutural que envolve a concentração espacial da tecnologia que ampara a indústria e principalmente da mercadoria essencial que gera valor no processo de trabalho industrial, qual seja, a força de trabalho. Para tanto, o ambiente urbano oferece, por intermédio do Estado e outras instituições, os denominados meios de consumo coletivo, atinentes a habitação, transporte como um fenômeno socioespacial que é mais do que as formas urbanas. É uma espécie de síntese dialética entre uma espacialidade difundida à totalidade do espaço social sob as formas de tecido urbano e de uma práxis típica da sociedade urbana, "hoje virtual, amanhã real". Trata-se de uma realidade totalizante que se desdobra na urbanização completa: do território e da sociedade. Cumpre aqui demarcar que o conceito ultrapassa a noção incutida no urbano adjetivo, que diz respeito à caracterização de aspectos relacionados à cidade propriamente dita. 
(acesso à fábrica), educação (treinamento), saúde (força de trabalho), entre outros elementos afins à diluição social dos custos de reprodução da força de trabalho.

Outro estudioso de inspiração marxista, Jean Lojkine (1981) amplia o escopo do argumento castellsiano ao trabalhar a idéia de condiçôes gerais de produção, que em última instância definiria o núcleo urbano (e suas articulaçôes sobre a rede regional) como a espacialidade propícia ao desenvolvimento capitalista, em termos similares ao urbanismo aventado por Soja. As condições gerais de produção são assim denominadas por abranger toda a estrutura socioespacial que põe o capital em movimento, circunscrita a um contexto urbano-regional. Corresponde à configuração espacial que abriga a concentração dos meios de produçãa, dos meios de circulação material e dos meios de consumo coletivo.

Em suma, o capitalismo é um modo de produção essencialmente urbano, que usa essa espacialidade em favor de sua reprodução ampliada. Fazendo a mesma afirmação de maneira invertida, a urbanização é a manifestação espacial do processo capitalista de acumulação, no sentido em que o tecido urbano (e regional) conforma um aparato socioespacial que sedia a acumulação de capital e favorece sua reprodução ampliada por concentrar as condiçóes gerais de produção, sendo estas a consubstanciação das várias facetas do ciclo capitalista, quais sejam: produção, circulação, consumo.

Os espaços regionais, formados pela articulação entre centros urbanos, são hierarquizados conforme a maior ou menor presença dessas condiçóes gerais que imprimem ritmo à dinâmica do capital: "a armação urbana aparece então antes de tudo através de sua rede de cidades (...) como uma distribuição social e espacial das diferentes condiçóes gerais da produção" (Lojkine, 1981, p.149). Dessa forma, é mister ter em mente que a funcionalidade sistêmica do capitalismo reside não somente na materialidade de cada centro urbano isolado, mas primordialmente em um plano socioeconômico-espacial de escala mais ampla, constituído pelos fluxos de relações estabelecidos entre uma miríade de núcleos de produção, donde constatamos que o capitalismo, além de se referenciar no ambiente urbano, caracteriza-se também pela sua projeção no plano regional.

Como acabamos de mencionar, a presença das chamadas condiçôes gerais da produção não é ubíqua. Pelo contrário, os espaços capitalistas apresentam como característica geral a distribuição não uniforme dos frutos de suas modernizações e dá origem a "urbanismos" marcados pelo desenvolvimento desigual em termos sociais e espaciais.

A simultaneidade de relações sociais e espaciais pode ser aferida com clareza na divisão regional do espaço entre centros dominantes e periferias dependentes, em relações espaciais de produção socialmente criadas e polarizadas; ou seja, no desenvolvimento geograficamente desigual. Essa teorização dos vínculos entre diferenciações sociais e espaciais traz implícita a dialética socioespacial: as relações (sociais e espaciais) de produção e as estruturas centro-periferia são dimensões não dissociáveis. "Ao contrário, os dois conjuntos de relações estruturadas (o social e o espacial) são não apenas homólogos, no sentido de provirem das mesmas origens no modo de produção, como também dialeticamente inseparáveis" (Soja, 1993, p.99).

Dessa forma, a assimetria fundamental no plano das relações sociais de produção capitalistas, resumida na dicotomia capital $v$ s trabalho, tem como contrapartida, no plano espacial, o descompasso entre centro e periferia. $\mathrm{O}$ avanço do capitalismo é intrinsecamente marcado pelo desenvolvimento desigual, pelo acesso social e espacialmente seletivo às benesses dos progressos técnicos e demais frutos do processo econômico. Assim, a geografia específica do capitalismo é caracterizada pela contigüidade ou mesmo justaposição de realidades sociais heterogêneas, muitas vezes antagônicas. 
A dinâmica espacial do capital exibe uma tendência centralizadora e vários são os elementos que se diferenciam geograficamente: a composição orgânica do capital, o valor de reprodução da força de trabalho (salários), níveis tecnológicos e o grau de acesso ao aparato de mais elevada tecnologia. Esses diferenciais regionais perpetuam-se em razão da concentração dos investimentos de capital, da infra-estrutura social e da presença hegemônica das condições gerais de produção em alguns pontos do espaço em detrimento de outros; o que finda por ratificar a concentração espacial dos meios de produção, circulação e consumo, e das atividades econômicas como um todo, significando, portanto, uma concentração espacial das oportunidades de desenvolvimento.

Soja (1993, p.140), endossando argumentos de Ernst Mandel (1976, 1987), identifica na dinâmica capitalista uma tendência à "transferência geográfica de valor", processo pelo qual o valor produzido em uma dada localidade periférica de menor densidade econômica é realizado em um centro mais desenvolvido, somando-se à base de acumulação deste através do intercâmbio comercial. $\mathrm{O}$ centro caracteriza-se como base exportadora de bens e serviços mais avançados, auferindo uma espécie de "mais-valia espacial", ainda que esse conceito não tenha sido sistematizado. Esse processo regionalmente desigual é o gatilho de uma configuração centro-periferia que marca caracteristicamente a espacialidade do capitalismo.

De toda essa senda teórica, cumpre aos nossos propósitos enfatizar o papel central da dialética socioespacial para a compreensão do capitalismo contemporâneo. $\mathrm{O}$ reconhecimento de que as contradições do modo de produção devem ser desvendadas pela investigação do espaço socialmente engendrado é capaz de nos conduzir a uma teoria social mais robusta no balizamento do planejamento. A base para uma teoria espacializada do planejamento no mundo contemporâneo requer necessariamente uma teoria da acumulação de capital em ambientes urbanos, que na nossa concepção de base lefebvreana adquire significante sinonímico à "economia política da produção social do espaço". Além disso, o planejamento do desenvolvimento regional só faz sentido a partir da percepção do caráter estruturalmente desigual da organização espacial específica do capitalismo.

Rastreamos o papel do espaço no planejamento ao identificar, com o auxílio de Henri Lefebvre e outros estudiosos neomarxistas do espaço, que a produção social do espaço é o mecanismo pelo qual o sistema capitalista encontra meios de se reproduzir amplamente. A espacialidade do urbano, refletida em formas e fenômenos socioespaciais, é o plano (material e imaterial) privilegiado da produção e da reprodução das relaçóes sociais capitalistas. Sutilmente, a teorização lefebvreana subverte a lógica dos teóricos convencionais do espaço, que tratam o elemento geográfico como um fator contingente (um custo) que limita a dinâmica do capital. Lefebvre, sem negar os obstáculos que a materialidade espacial (o espaço banal, diria François Perroux ${ }^{25}$ ) impõe ao movimento do capital, enfatiza que, contraditoriamente, a dialética socioespacial - cuja síntese é o urbano pleno de relações sociais - é a instância que oxigena o capitalismo em sua corrida para chegar cada vez mais longe.

A ponte requerida entre o papel teórico-analítico do espaço e a perspectiva política, no âmbito de um arcabouço econômico planejador, é bem construída por Doreen Massey:

o entendimento da organização geográfica é fundamental para se compreender a economia e a sociedade. A geografia da sociedade faz diferença no modo como esta funciona. Se isso é verdade em
25 Francois Perroux (1964, 1967), pensador da economia política do espaco, pode ser considerado pioneiro numa sistematização conceitual que concebe o espaco como elemento multidimensional. 0 autor propõe uma distinção entre o espaço banal, concreto, "geonômico" e o espaço abstrato ou "econômico". O espaço banal diz respeito ao plano concreto, o continente cujo conteúdo é a vida social em sua totalidade. 0 espaço econômico, por sua vez, diz respeito a um plano paralelo abstrato envidado pelas múltiplas relações sociais e fluxos econômicos "delocalizados", que conferem ao espaco um caráter multifacetado, composto por pelo menos três dimensões analíticas: é um espaço definido por um "plano relacional" (onde são estabelecidas relações entre elementos sociais e econômicos, como firmas e seus fornecedores de insumos e compradores de produtos); é um espaço caracterizado como um "campo de forças" (centros dos quais emanam forcas centrípetas e centrífugas); e é um espaço visto como um "agregado homogêneo" (homogeneous aggregate), habitado por unidades econômicas que se avizinham e apresentam estruturas mais ou menos homogêneas. 
26 "Regions and space are a neglected but necessary dimension of the theory and the practice of economic development. Without the spatial point of view, the analysis is incomplete".

Lucas Linhares é economista do BNDES, mestre em Economia pelo Cedeplar/UFMG. E-mail: cucalinhares@gmail.com

Artigo recebido em setembro de 2008 e aprovado para publicação em janeiro de 2009. termos analiticos, também oé em termos politicos. Para que haja alguma esperança de alterar a geografia fundamentalmente desigual da economia e da sociedade [capitalista], faz-se necessária uma politica que ligue as questôes da distribuição geográfica às da organização social e econômica. (Massey,1984 apud Soja, 1993, p.84)

Nesses termos, o regime de acumulação seria moldado pela produção social do espaço, donde a compreensão do capitalismo urbano-industrial contemporâneo e das relaçôes sociais que lhe são características não prescinde de uma perspectiva espacializada. Reafirmamos assim o papel do espaço na teoria social crítica. "As regióes e o espaço conformam uma negligenciada, porém necessária, dimensão da teoria e da prática do desenvolvimento econômico. Sem o ponto de vista espacial, a análise é incompleta" ${ }^{\text {26 }}$ (Friedmann \& Alonso, 1964, p.1).

Diante disso, chegamos ao entendimento de que uma teoria do planejamento deve ser necessariamente espacializada. Endossamos a perspectiva grega além-milenar de que a socioeconomia das cidades e regióes constituem o objeto de reflexão da teoria do planejamento. O espaço, hoje mais do que nunca, é revelador da realidade econômica e social, porquanto deve ser concebido criticamente de forma a sustentar um projeto de desenvolvimento. Sendo o âmbito econômico a esfera hegemônica no capitalismo urbano-industrial, o planejamento do desenvolvimento prima por orientar a configuração econômicoespacial real por uma via emancipatória que signifique melhores condições de reprodução ao conjunto da sociedade, de sorte que esta adquira maior autonomia na apropriação e produção social de seu próprio espaço.

\section{REFERÊNCIAS BIBLIOGRÁFICAS}

ARISTÓTELES (1997). Politica. Brasília: Editora UnB.

CASTELLS, M. (1977). The Urban Question. Londres: Edward Arnold. . (1999). A Era da Informação: Economia, Sociedade e Cultura - A Sociedade em Rede. São Paulo: Paz e Terra.

EDITORA NOVA CULTURAL (2000). Aristóteles - Vida e Obra. São Paulo: Nova Cultural.

FRIEDMANN, J.; ALONSO, W. (eds) (1964). Regional Development and Planning. Cambridge, Massachussets: MIT Press.

FRIEDMANN, J. e WEAVER, C. (1979). Territory and Function: the evolution of regional planning. Los Angeles: University of California Press.

FRIEDMANN, J. (1987). Planning in the Public Domain: from knowledge to action. Princeton: Princeton University Press.

GOTTDIENER, M. (1993). A Produção Social do Espaço Urbano. São Paulo: EDUSP.

HARVEY, D. (1973). Social Justice and the City. Baltimore: Johns Hopkins University Press. . (1975). The Geography of Capitalist Accumulation: a reconstruction of Marxian Theory. Antipode, 7, pp. 9-21.

. (1977). Labor, Capital and Class Struggle Around the Built Environment in Advanced Capitalist Societies. Politcs and Society,6, pp.265-295.

. (1992). A Condição Pós-Moderna: uma pesquisa sobre as origens da mudança cultural. São Paulo: Ediçóes Loyola. 
HERRERA, R. (2006). The Neoliberal "Rebirth" of Development Economics. Monthly Review, v.58, nº1, maio de 2006.

IONESCU, G. (1976). The Political Thought of Saint-Simon. New York: Oxford University Press.

KUHN, T. (1962). The Structure of Scientific Revolutions. Chicago: Chicago University Press.

LEFEBVRE, H. (1976). The survival of capitalism. London: Allison \& Busby. . (1991). The production of space. Oxford: Blackwell. . (1999). A Revolução Urbana. Belo Horizonte: UFMG. . (2001). O Direito à Cidade. São Paulo: Centauro.

LENZER, G. (ed.) (1998). Auguste Comte and Positivism: the essential writings. London: Transaction Publishers.

LOJKINE, J. (1976). Contribution to a Marxist Theory of Capitalist Urbanization. In: PICKVANCE, C. (org.). Urban Sociology. London: Tavistock Publications.

. (1981). O Estado Capitalista e a Questão Urbana. São Paulo: Martins Fon-

tes.

LÖSCH, A. (1954). The Economics of Location. New Haven: Yale University Press.

MANDEL, E. (1976). Capitalism and Regional Disparities. Southwest Economy and Society 1, pp.41-47.

. (1987) Late Capitalism. London: Verso.

MARSHALL, A. (1982)[1890]. Princípios de Economia: tratado introdutório. São Paulo: Abril Cultural, v.I, livro IV, cap.9-10. (Coleção "Os Economistas")

MARX, K. (1999)[1867]. O Capital: Crítica da Economia Política. 17ª ed. Rio de Janeiro: Civilização Brasileira.

MASSEY, D. (1984). Spatial Divisions of Labour: social structures and the Geography of Production. Londres: Macmillan Press.

PECQUEUR, B. e ZIMMERMANN, J.B. (2005). Fundamentos de uma economia da proximidade. In: DINIZ, C. e LEMOS, M. (orgs.) Economia e Território. Belo Horizonte: Editora UFMG.

PERROUX, F. (1964). Economic Space: Theory and Applications. In: FRIEDMANN, J.; ALONSO, W. (eds). Regional Development and Planning. Cambridge, Massachussets: MIT Press.

(1967). A economia do século XX. Lisboa: Livraria Morais Editora.

RICARDO, D. (1996)[1817]. Princípios de Economia Politica e Tributação. São Paulo: Nova Cultural. (Coleção "Os Economistas").

SMITH, A. (1996)[1776]. A riqueza das naçōes: investigação sobre sua natureza e suas causas. São Paulo: Nova Cultural. (Coleção "Os Economistas").

SOJA, E. (1993). Geografias pós-modernas: a reafirmação do espaço na teoria social crítica. Rio de Janeiro: Jorge Zahar. . (2000). Postmetropolis: critical studies of cities and regions. Blackwell.

SOUSA SANTOS, B. de (2005)[1987]. Um discurso sobre as ciências. 3.ed. São Paulo: Cortez.

VON THÜNEN, J. H. (1966) [1826]. The Isolated State. Volume 1. Oxford: Pergamon Press.

WALRAS, L. (1996). Compêndio dos Elementos de Economia Politica Pura. São Paulo: Nova Cultural (Coleção "Os Economistas"). 
A B S T R A C T In modern capitalist societies, the Planning Theory and Praxis reflects a consolidation of a "mechanical" rationality model which treats social phenomena as they could be described by universal and immutable laws. Specifically in the field on Political Economy which is dominated by neoclassical corpus, searching for general theoretical schemes tends to neglect the "space" as analytical category. Initially, this paper aims to make an epistemological discussion and to make a critical assessment of the embodiment of the "mechanical paradigm" by the Planning Theory. Moreover, this paper intends to put the space on foreground of the Social Theory, i.e., the space is taken as a fundamental category to comprehend the capitalist dynamics. Looking into socially built space allows us to reach a socio-spatial dialectics and hence a more comprehensive Social Theory and a stronger Planning Theory.

K E Y W O R D S Planning; socio-spatial dialectics; modernity; social space. 